\title{
O PROGRAMA DE AQUISIÇÃO DE ALIMENTOS NO TOCANTINS: AS CONDIÇÕES SOCIAIS DE REALIZAÇÃO DE MERCADOS COM PRÁTICAS DE ACESSO INDIVIDUAIS E COLETIVAS
}

\author{
THE PROGRAM OF ACQUISITION OF FOODS IN \\ TOCANTINS: THE SOCIAL CONDITIONS OF \\ ACCOMPLISHMENT OF MARKETS WITH INDIVIDUAL \\ AND COLLECTIVE PRACTICES OF ACCESS
}

\author{
Gildene Soares Carvalho \\ Instituto Interamericano de Cooperação para a Agricultura - Palmas -TO - \\ Brasil
}

Antônio José Pedroso Neto

Universidade Federal do Tocantins - Palmas -TO - Brasil

\begin{abstract}
Resumo: O objetivo desse artigo é apresentar os resultados de uma pesquisa realizada no Estado do Tocantins sobre o mercado institucional que envolve o Programa de Aquisição de Alimentos e a agricultura familiar. Conforme os marcos da sociologia econômica, os mercados são estruturas sociais que precisam de inúmeras condições sociais, culturais, políticas e econômicas para se configurarem. Dessa perspectiva, estabelecemos uma questão geral: como as relações sociais e mercantis acontecem na prática em configurações concretas, localizadas e delimitadas de mercado institucional da agricultura familiar? Para responder essa questão, utilizamos a estratégia metodológica de analisar, comparativamente, duas configurações empíricas desse mercado: uma em que os agricultores familiares acessaram o Programa de Aquisição de Alimentos de modo coletivo e outra em que o acessaram de modo individual. Para isso, recorremos a documentos, realizamos entrevistas e aplicamos questionários. $O$ trabalho apresenta os marcos institucionais e alguns balanços da execução do Programa de Aquisição de Alimentos no Brasil e no Estado do Tocantins. Apresenta uma descrição da morfologia das duas configurações e uma descrição de diversos processos modais mais específicos, do processo mais geral de construir e estabilizar as relações entre os agricultores familiares e os demais agentes do mercado institucional da agricultura familiar.
\end{abstract}


Palavras-chave: Programa de Aquisição de Alimentos, Agricultura Familiar, Mercado Institucional, Sociologia Econômica.

Abstract: The objective of that article is to present the results of a research accomplished in the State of Tocantins on the institutional market that involves the Program of Acquisition of Foods and the family agriculture. According to the marks of the economical sociology, the markets are social structures that. It needs countless social, cultural, politics and economical conditions for if they configure. Of that perspective, we established a general subject: how do the social and mercantile relationships happen in practice in configurations concrete, located and delimited of institutional market of the family agriculture? To answer that subject, we used the methodological strategy of analyzing, comparatively, two empiric configurations of that market: one in that the family farmers accessed the Program of Acquisition of Foods in collective our individual way. For that, we fell back upon documents, we accomplished interviews and we applied questionnaires. The work presents the institutional marks and some swingings of the execution of the Program of Acquisition of Foods in Brazil and in the State of Tocantins. It presents a description of the morphology of the two configurations and a description of several more specific modal processes of the most general process of to build and to stabilize the relationships between the family farmers and the other agents of the institutional market of the family agriculture.

Keywords: Food Acquisition Program, Institutional Market, Family Farmer, Economic Sociology.

\section{Introdução}

O Programa de Aquisição de Alimentos (PAA) é uma política pública do estado brasileiro que atende, ao mesmo tempo, duas demandas: a da criação de mercados para os produtos dos agricultores familiares; e a segurança alimentar, ao ofertar alimentos para a população que se encontra em situação de insegurança alimentar. Da perspectiva do marco legal, o PAA foi instituído pelo governo brasileiro no ano de 2003, com a finalidade principal de "incentivar a agricultura familiar, compreendendo ações vinculadas à distribuição de produtos agropecuários para pessoas em situação de insegurança alimentar e à formação de estoques estratégicos" (BRASIL, Lei N ${ }^{\circ}$ 10.696/2003, Art. 19).

Neste artigo, será utilizado o termo mercado institucional para descrever a relação que se estabelece entre o PAA e a agricultura familiar. O conceito não é novo, mas passou a ser utilizado com mais frequência após a criação do PAA. De modo geral, a maioria das definições adotadas sobre o mercado institucional da agricultura 
familiar, formado a partir do PAA, baseia-se no entendimento de que esse mercado se realiza através da compra de alimentos pelas três esferas de governo - municipal, estadual e federal - sem a necessidade de licitação, com a finalidade de doar para as entidades socioassistenciais. De fato, é o mercado em que o estado assume o papel de regular e estabelecer normas de funcionamento, de definir os preços de referência dos alimentos, de definir quem são os compradores e os consumidores e de garantir os recursos financeiros para sua manutenção (GRISA, 2010).

Tendo como referência a sociologia econômica, e mais pontualmente a sociologia dos mercados, temos que, como todos os mercados, o mercado institucional da agricultura familiar não é algo que acontece espontaneamente. Ao contrário, é o resultado de uma construção social, a partir de um conjunto de relações sociais baseadas na cultura, na política e na cognição.

os mercados pressupõem espaços sociais onde trocas repetidas ocorrem entre compradores e vendedores sob um conjunto de regras formais e informais que governam relações entre competidores, fornecedores e clientes. Esses campos operam de acordo com entendimentos locais e regras, além de convenções formais e informais que guiam a interação, facilitam o comércio, definem os produtos que são produzidos, e, de fato, são constitutivas dos produtos, assim como proveem estabilidade para compradores, vendedores e produtores. Esses mercados dependem de governos, leis e entendimentos culturais mais amplos nos quais se baseia a atividade mercantil. (FLIGSTEIN e DAUTER, 2007, p. 489).

A sociologia econômica é uma disciplina que estuda os fatos, processos e estruturas da esfera econômica da sociedade a partir dos conceitos e princípios epistemológicos, teóricos e metodológicos das ciências sociais (SWEDBERG, 2003; BOURDIEU, 2000). Há uma gama de objetos sobre os quais os sociólogos da economia detiverem sua atenção, considerando suas dimensões políticas, culturais, cognitivas e sociais: mercados, campos organizacionais, tecnologia, etc. (SWEDBERG, 2003). E os sociólogos da economia que se empenharam em estudar configurações concretas de mercados (POLANYI, 2000; BOURDIEU, 2000; GARCIA-PARPET, 2002 e 2003; FLIGSTEIN, 2003), de modo geral, compartilham que "os mercados são estruturas sociais caracterizadas 
por relações sociais extensas entre firmas, trabalhadores, fornecedores, clientes e governos" e, a partir disso, empregam diversas ferramentas teóricas e metodológicas para compreender e revelar "as origens, operações e dinâmicas dos mercados como estruturas sociais" (FLIGSTEIN e DAUTER, 2007, p. 481).

A inserção dos agricultores familiares no PAA no Estado do Tocantins, implicou que construíssem relações formais e informais com o estado - normas, contratos, leis, decretos, acordos tácitos - e com as instituições socioassistenciais participantes do programa. Dito de outro modo, tal inserção resultou de uma construção social feita a partir de um conjunto de relações sociais, pré-existentes e novas. Sendo assim, temos algumas questões. Como as relações sociais e mercantis acontecem na prática em configurações concretas, localizadas e delimitadas do PAA? Quais relações, agentes, interesses, acordos, etc. estão presentes e como são criados, mantidos, incentivados ou constrangidos a terem perenidade? Quais conflitos, discordâncias e fissões estão presentes, implícita ou explicitamente, e como são dissipados, diminuídos ou apassivados?

Como estratégia metodológica para responder essas questões, observamos e comparamos sistematicamente duas configurações empíricas do mercado institucional da agricultura familiar no Estado do Tocantins - utilizamos documentos, entrevistas e questionários. Uma configuração de vínculo coletivo dos agricultores familiares com o PAA, localizada no município de Araguaína, TO. Nela os agricultores acessaram o programa por meio da Associação dos Agricultores Familiares do Reassentamento Mirindiba. A unidade governamental executora deste PAA, é a CONAB, órgão da esfera governamental federal. Doravante utilizaremos o termo PAA Conab para identificar a configuração de caráter coletivo. E observamos uma configuração de vínculo individual dos agricultores familiares com o PAA, localizada no município de Palmas, TO. Nela os agricultores acessaram o programa individualmente, sem a interveniência de uma organização coletiva. A unidade governamental executora deste PAA, é o Instituto de Desenvolvimento Rural do Tocantins (RURALTINS), órgão do Governo do Estado do Tocantins. Usaremos o termo PAA Estadual para identificar a configuração de acesso individual. 
Qualquer configuração de vínculo dos agricultores familiares com o PAA se dá a partir de alguns marcos institucionais compartilhados: as normas de definição de agricultora familiar, as normas de funcionamento do PAA - vínculos, pagamentos, produtos, produtores, consumidores, etc. -, a formação da estrutura organizacional, os papéis e as contrapartidas de outras instituições envolvidas - municipais, estaduais e federais e, também, da sociedade civil, etc. -, normas sanitárias relativas aos produtos, diversos incentivos e subsídios financeiros do governo federal, etc. Sendo assim, as duas configurações analisadas são variantes que nos permitem revelar estruturas, em grande medida, presentes no conjunto das configurações possíveis que de fato acontecem em outros municípios e estados brasileiros.

Este artigo tem a seguinte estrutura. $\mathrm{Na}$ segunda seção, apresentamos o formato institucional do PAA no Brasil e no Estado do Tocantins: agentes individuais e institucionais, suas funções, as normas, as modalidades, a estrutura organizacional e séries históricas dos montantes de recursos financeiros movimentados. Na terceira seção, apresentamos a metodologia. Na quarta seção, apresentaremos diferenças entre os dois grupos de agricultores familiares: sexo, renda, escolaridade, situação da propriedade da terra, produção e relação com associações. E, por fim, na quinta seção apresentamos pontos modais das relações dos agricultores com o PAA: canais de comercialização, justificativas da opção pelo PAA, seleção dos beneficiários e agricultores, conflitos e acordos em relação aos preços, quantidades e prazos - considerando diferenças entre as duas configurações.

\section{Programa de Aquisição de Alimentos: institucionalidades e realizações no Brasil e no Tocantins}

Nesta seção, vamos apresentar o formato institucional do PAA. Suas finalidades são: promover a inclusão econômica e social da agricultura familiar; incentivar o consumo e a valorização dos alimentos produzidos pela agricultura familiar; promover o acesso à alimentação por pessoas em situação de insegurança alimentar e nutricional; promover $\mathrm{o}$ abastecimento alimentar por meio de compras governamentais de alimentos; apoiar a formação de estoques pelas cooperativas; fortalecer circuitos locais e regionais e redes de 
comercialização; estimular o cooperativismo e o associativismo (BRASIL, Decreto $N^{0} 7.775 / 2012$, Art. 2). A figura 01 apresenta o formato de execução do PAA, com a identificação do público participante.

Figura 01. Desenho institucional do PAA

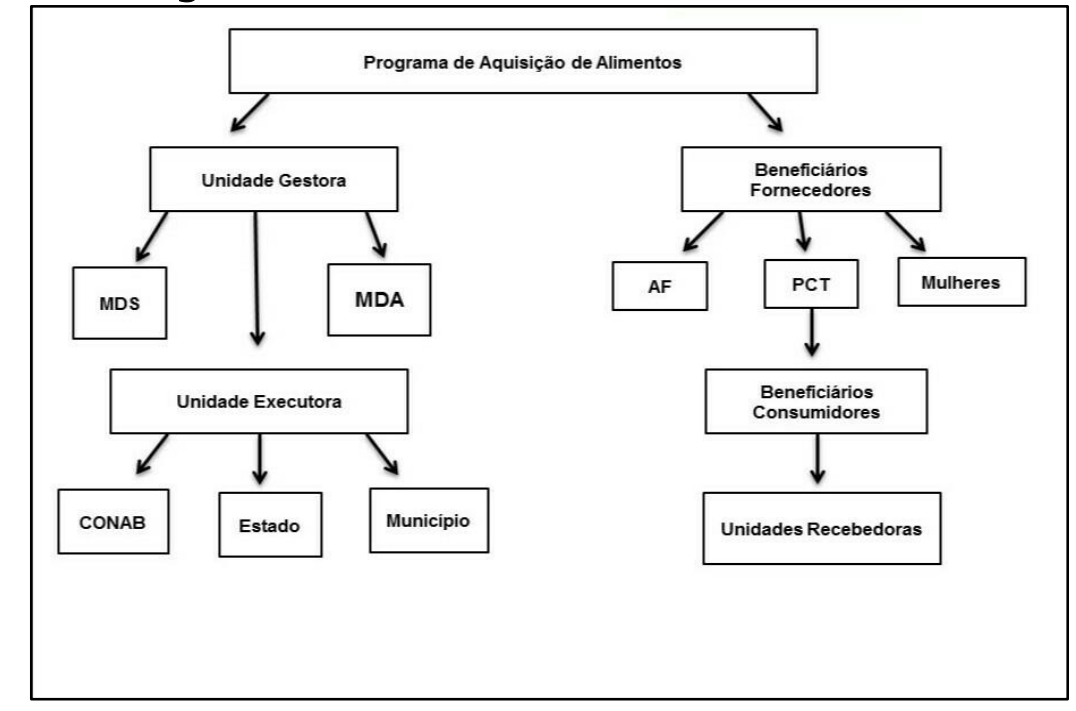

Fonte: Elaborado pelos autores a partir de dados da pesquisa, 2015.

No mercado do PAA, os beneficiários fornecedores são agricultores familiares, silvicultores, aquicultores, extrativistas, pescadores, povos indígenas, quilombolas e demais povos e comunidades tradicionais. Eles devem ser detentores da Declaração de Aptidão ao Programa Nacional de Fortalecimento da Agricultura Familiar (PRONAF), isto é, declaração de que vendem seus produtos para o programa de forma individual ou coletiva através de associações ou cooperativas (BRASIL, Lei 11.326/2006, Art. 3).

Os beneficiários consumidores são os indivíduos que se encontram em situação de insegurança alimentar e nutricional e são atendidos pela rede socioassistencial e pelos equipamentos de alimentação e nutrição, como escolas, restaurantes populares e cozinhas comunitárias que lhes servem alimentos processados (BRASIL, Decreto No 7.775/2012, Art. 4).

A instância de coordenação do PAA, prevista no artigo 19 da Lei 10.696/2003 e regulamentada pelo artigo 21 do Decreto 7.775/2012, se dá através do Grupo Gestor do Programa de Aquisição de Alimentos (GGPAA), responsável por criar as normas necessárias para regulamentar o funcionamento desse mercado. O GGPAA contempla, em sua estrutura, a participação de seis ministérios sendo eles: Ministério do 
Desenvolvimento Social e Combate à Fome (MDS); Ministério do Desenvolvimento Agrário; Ministério da Agricultura, Pecuária e Abastecimento; Ministério do Planejamento, Orçamento e Gestão; Ministério da Fazenda; e o Ministério da Educação.

Nota-se que a estrutura do GGPAA não contempla a participação de representantes da sociedade civil e nem das unidades executoras estados e municípios -, exceto a CONAB, que é parte da estrutura do Ministério da Agricultura, Pecuária e Abastecimento, estando representada por esse ministério no respectivo grupo. Se, por um lado, o PAA não contempla a participação das unidades executoras em sua instância de gestão - GGPAA -, por outro, percebe-se que a participação da sociedade civil foi garantida na gestão do programa, em 2012, quando foi criado o Comitê Consultivo vinculado ao GGPAA (BRASIL, Resolução Nº 49/2012, Art. 1)

$\mathrm{Na}$ análise sobre a atuação do GGPAA, identificamos que, basicamente, ele concentra sua atuação nos temas relacionados aos preços, pagamentos de produtos e destinação dos alimentos. Sendo, portanto, pouco debatido temas considerados estratégicos para o funcionamento desse mercado, a exemplo da legislação sanitária dos produtos oriundos da agricultura familiar e o fortalecimento do cooperativismo e associativismo.

A estrutura de funcionamento do PAA encontra-se organizada por modalidades, sendo elas: Compra com Doação Simultânea, Compra Direta, Incentivo à Produção e ao Consumo de Leite, Apoio à Formação de Estoques, Compra Institucional e Aquisição de Sementes. Encontrase no Quadro 01, a descrição das unidades executoras e os valores de cada modalidade.

Quadro 01. Modalidades e Valores do PAA

\begin{tabular}{|l|c|c|c|}
\hline \multicolumn{1}{|c|}{ Modalidade } & Unidade Executora & $\begin{array}{c}\mathbf{R} \$ \mathrm{p} / \text { Unidade } \\
\text { Familiar }\end{array}$ & $\begin{array}{c}\mathbf{R} \$ \mathrm{p} / \text { Organização } \\
\text { Fornecedora }\end{array}$ \\
\hline Doação Simultânea & $\begin{array}{c}\text { CONAB, Estados, } \\
\text { Municípios }\end{array}$ & $6.500,00 \mathrm{p} /$ ano & $2.000 .000,00 \mathrm{p} /$ ano \\
\hline Compra Direta & CONAB & $8.000,00 \mathrm{p} /$ ano & $500.000,00 \mathrm{p} /$ ano \\
\hline PAA Leite & $\begin{array}{c}\text { Estados do Nordeste, } \\
\text { e região norte de MG }\end{array}$ & $\begin{array}{c}4.000,00 \\
\mathrm{p} / \mathrm{semestre}\end{array}$ & - \\
\hline $\begin{array}{l}\text { Formação de } \\
\text { Estoques }\end{array}$ & CONAB & $8.000,00 \mathrm{p} /$ ano & $1.500 .000 \mathrm{p} /$ ano \\
\hline Compra Institucional & $\begin{array}{c}\text { União, Estados, } \\
\text { Municípios e DF }\end{array}$ & $20.000,00 \mathrm{p} /$ ano & $\begin{array}{c}6.000 .000,00 \text { por órgão } \\
\text { comprador }\end{array}$ \\
\hline
\end{tabular}




\begin{tabular}{|l|l|l|l|}
$\begin{array}{l}\text { Aquisição de } \\
\text { Sementes }\end{array}$ & CONAB & $16.000,00 \mathrm{p} /$ ano & $\begin{array}{c}6.000 .000,00 \mathrm{p} / \\
\text { organização fornecedora }\end{array}$ \\
\hline
\end{tabular}

Fonte: Elaborado pelos autores a partir do Decreto $N^{\circ} 8.293 / 2014$.

As modalidades, Compra Institucional e Aquisição de Sementes, ampliou o mercado institucional da agricultura familiar. No caso específico da Aquisição de Sementes, essa modalidade delimitou a inclusão do PAA no mercado das sementes no Brasil, que possui regulamentação própria tanto para produtores, quanto para o registro das sementes produzidas (BRASIL, Decreto 8.293/2014, Art. 1)

Outra frente desse mercado é a aquisição de produtos agroecológicos ou orgânicos. Para esses produtos, o PAA garante o pagamento de preços de referência com acréscimo de até $30 \%$ em relação aos preços dos produtos convencionais. No entanto, a aquisição desses produtos se dá mediante apresentação de documento de certificação de origem. Na prática, isso não é algo tão simples para os agricultores conseguirem, porque o processo de certificação desses produtos exige a participação de outras instituições, por exemplo, das empresas prestadoras de serviços de assistência técnica e extensão rural.

A destinação dos alimentos adquiridos no âmbito do PAA visa atender as seguintes condições:

$$
\begin{aligned}
& \text { I- o consumo de pessoas ou famílias em situação de } \\
& \text { insegurança alimentar e nutricional; II - o abastecimento da } \\
& \text { rede socioassistencial; III - o abastecimento de equipamentos } \\
& \text { de alimentação e nutrição; IV - o abastecimento da rede pública } \\
& \text { e filantrópica de ensino; V - a constituição de estoques } \\
& \text { públicos de alimentos, destinados a ações de abastecimento } \\
& \text { social ou venda; e VI - o atendimento a outras demandas } \\
& \text { definidas pelo GGPAA (BRASIL, Decreto } \mathrm{N}^{\circ} 7.775 / 2012 \text {, Art. 9). }
\end{aligned}
$$

Uma consideração relevante sobre as entidades socioassistenciais consideradas aptas para receberem as doações de alimentos adquiridos no âmbito do PAA é a exigência relativa ao credenciamento no Conselho Municipal de Assistência Social, que vigora desde 2014. No Tocantins, percebe-se que tal exigência tem dificultado a participação de algumas entidades como beneficiárias consumidoras do PAA, principalmente daquelas consideradas como as mais carentes. Isso porque elas enfrentam dificuldades para garantir o registro nos respectivos 
conselhos, principalmente pela quantidade de documentos que é exigido. E, por sua vez, os conselhos têm demonstrado resistências quanto à inclusão de mais essa tarefa como parte de suas atribuições.

\subsection{A execução do PAA no período de 2003 a 2014 no Brasil}

Em julho de 2003, o Governo Federal colocou em execução o PAA, com um orçamento de $R \$ 400$ milhões de reais. Considerando que só restavam seis meses para finalizar o ano, foi possível executar apenas $\mathrm{R} \$ 145.014 .750,90$ do valor disponibilizado. Com esse recurso, foram adquiridas 7.800 toneladas de alimentos, de 41.454 agricultores familiares, doados para 80.427 pessoas que se encontravam em situação de insegurança alimentar.

No período de mais de onze anos, foram investidos no PAA mais de 5 bilhões de reais, possibilitando a participação de mais de 1.400.000 agricultores familiares, com aquisição de mais de 4 milhões de toneladas de alimentos que foram doados para mais de 321.995 .078 pessoas. Na Tabela 01 será apresentado o resultado da execução do PAA no Brasil, no período de 2003 a 2014.

Tabela 1. Dados de execução do PAA no Brasil de 2003 a 2014

\begin{tabular}{ccccc}
\hline Ano & $\begin{array}{c}\text { Volume de } \\
\text { Recursos (R\$) }\end{array}$ & $\begin{array}{c}\mathbf{N}^{\circ} \text { de } \\
\text { Agricultores } \\
\text { Familiares }\end{array}$ & $\begin{array}{c}\mathbf{N}^{\circ} \text { de } \\
\text { pessoas } \\
\text { atendidas }\end{array}$ & $\begin{array}{c}\text { Quantidade } \\
\text { de Alimentos } \\
\text { (toneladas) }\end{array}$ \\
\hline 2003 & $145.014 .750,90$ & 41.464 & 80.427 & 7.800 \\
\hline 2004 & $181.074 .211,46$ & 68.697 & 1.794 .487 & 248.805 \\
\hline 2005 & $295.582 .051,59$ & 69.692 & 3.854 .681 & 277.033 \\
\hline 2006 & $497.833 .620,40$ & 150.919 & 8.874 .134 & 462.599 \\
\hline 2007 & $465.105 .404,51$ & 134.574 & 11.408 .530 & 418.661 \\
\hline 2008 & $512.036 .873,93$ & 138.285 & 12.796 .110 & 396.380 \\
\hline 2009 & $591.244 .764,73$ & 142.381 & 11.030 .346 & 500.491 \\
\hline 2010 & $675.133 .142,78$ & 156.964 & 18.875 .174 & 462.429 \\
\hline 2011 & $667.325 .490,26$ & 160.011 & 19.812 .686 & 517.922 \\
\hline 2012 & $838.460 .435,51$ & 185.489 & 20.445 .645 & 528.714 \\
\hline 2013 & $442.703 .401,85$ & 96.533 & 11.058 .526 & 280.073 \\
\hline 2014 & $573.285 .819,94$ & 112.267 & 201.964 .332 & 328.022 \\
\hline
\end{tabular}


Fonte: MDS/2014

Conforme demonstrado na Tabela 1, de modo geral, com algumas flutuações há um crescimento do volume de recursos de 2003 a 2012 ano com maior volume na série histórica -, seguido de uma queda brusca em 2013 e 2014.

Enfim, ainda que se possa verificar inúmeras dificuldades relacionadas à execução do PAA, em mais de onze anos de existência, ele alcançou resultados significativos; garantiu a inserção de 1.457.276 agricultores familiares nesse mercado e dou mais de 4.428.929 toneladas de alimentos para 321.995 .078 pessoas que se encontravam em situação de insegurança alimentar. E, ainda, no decorrer das atividades, o mercado foi fortalecido e expandido, por exemplo com a inclusão das modalidades Compra Institucional e Aquisição de Sementes.

\subsection{O PAA no Estado do Tocantins}

No ano de 2003, o RURALTINS - órgão oficial do governo estadual, responsável pelos serviços de Assistência Técnica e Extensão Rural e vinculado à Secretaria do Desenvolvimento da Agricultura e Pecuária -, foi escolhido pelo governo estadual para executar o PAA. No mesmo ano teve início à execução do PAA nos municípios pertencentes ao Consórcio de Segurança Alimentar e Desenvolvimento Local ${ }^{1}$, atualmente denominado Território da Cidadania do Bico do Papagaio. Em seguida, a execução foi expandida para os municípios com concentração de projetos de assentamentos de reforma agrária.

Até junho de 2014, o PAA Estadual foi executado pelo RURALTINS via instrumento de convênio e somente a partir de agosto de 2014 o

\footnotetext{
'Os Consórcios de Segurança Alimentar e Desenvolvimento Local, foram criados em 2004, com a finalidade de promover a Segurança Alimentar através de uma política territorial com foco na promoção de política de geração de emprego e de renda. Tinha por objetivo construir um desenho institucional de política diferente envolvendo as três esferas de governo (Federal, Estadual e Municipal).
} 
programa passou a ser executado via Termo de Adesão². Observemos como o gestor público retrata as mudanças ocorridas no formato de execução do programa.

Eu destacaria, reduziu bastante a burocracia e a agilidade no pagamento do agricultor e a questão de gerenciamento né. Hoje é possível você acessar o sistema e ver quem está cadastrado, quem não tá, quem comprou, quem vendeu, quem recebeu. Isso só em sistema de relatórios é eu pego isso do exercício 2015, 2014, enfim. Então eu tenho um gerenciamento mais funcional do que na época dos convênios, que cada Estado tinha sua planilha e hoje esse gerenciamento, eu em qualquer lugar que tem internet, estando dentro do Estado ou fora, eu consigo gerenciar o programa a distância também (Gestor Público).

A partir dessa constatação, ressaltamos que a execução do PAA Estadual, via Termo de Adesão, permitiu que o programa fosse executado pelos estados e municípios sem a necessidade de contrapartida com recursos financeiros. Essa necessidade, muitas vezes, recorrentemente foi utilizada para justificar atrasos na execução do programa, bem como, ausências de acompanhamento das ações de aquisições de produtos juntos aos agricultores familiares.

A CONAB começou a execução do PAA no Tocantins no início de 2004, colocando em prática os projetos que haviam sido acordados com os agricultores familiares ainda no último semestre de 2003. Sua atuação, inicialmente, foi concentrada nas regiões Sul e Sudeste do estado, em decorrência da existência de quatro armazéns de sua propriedade nessas localidades, isto é, de estruturas que seriam utilizadas para o recebimento dos produtos adquiridos por meio da modalidade Formação de Estoques.

Analisando a participação dos governos municipais como unidades executoras do programa, constatamos que apenas duas das 139 cidades do estado se comprometeram diretamente com a execução do PAA: Araguaína, localizada na região norte e segunda maior cidade do estado, iniciou a execução em 2007 e continua até os dias atuais; e Palmas, a capital, localizada na região central e a maior cidade,

2 Termo de Adesão $\mathrm{N}^{\mathrm{o}}$ : 0013/2012, Modelo Puro - Estado execução indireta (RURALTINS), publicado no Diário Oficial da União em 29/10/2012. 
executou apenas um convênio que iniciou em 2008 e foi encerrado em 2010. Na tabela 2, estão apresentados os dados referentes à execução do PAA no estado no período de 2003 a 2014. 
Tabela 2. Dados de execução do PAA no Tocantins de 2003 a 2014

\begin{tabular}{c|c|c|c|c}
\hline Ano & $\begin{array}{c}\text { Volume de } \\
\text { Recursos (R\$) }\end{array}$ & $\begin{array}{c}\mathbf{N}^{\circ} \text { de } \\
\text { Agricultores } \\
\text { Familiares }\end{array}$ & $\begin{array}{c}\mathbf{N}^{\circ} \text { de } \\
\text { pessoas } \\
\text { Atendidas }\end{array}$ & $\begin{array}{c}\text { Quantidade de } \\
\text { Alimentos } \\
\text { (toneladas) }\end{array}$ \\
\hline 2003 & $4.192 .754,50$ & 1.700 & - & - \\
\hline 2004 & $4.033 .587,96$ & 1.694 & - & 4 \\
\hline 2005 & $1.672 .856,55$ & 980 & 32.193 & 246 \\
\hline 2006 & $3.597 .963,06$ & 1.986 & 171.108 & 3.864 \\
\hline 2007 & $4.021 .938,36$ & 1.500 & 134.933 & 2.828 \\
\hline 2008 & $6.119 .695,04$ & 2.621 & 135.219 & 2.500 \\
\hline 2009 & $6.857 .911,34$ & 3.009 & 102.070 & 2.435 \\
\hline 2010 & $4.404 .115,97$ & 1.913 & - & 1.620 \\
\hline 2011 & $7.670 .106,57$ & 2.658 & 212.880 & 2.422 \\
\hline 2012 & $5.086 .370,23$ & 1.912 & 330.052 & 1.677 \\
\hline 2013 & $7.629 .099,31$ & 2.175 & 191.105 & 2.334 \\
\hline 2014 & $2.438 .380,10$ & 551 & 47.153 & 864 \\
\hline TOTAL & $57.724 .778,99$ & 22.699 & 1.356 .713 & 20.794 \\
\hline
\end{tabular}

Fonte: MDS/SESAN, 2014

Conforme demonstrado na Tabela 02, em doze anos, foram investidos mais de 57 milhões de reais na execução do PAA no Tocantins. Isso significou o atendimento de mais de 22 mil agricultores e a aquisição de mais de 20 mil toneladas de alimentos que foram doados para mais de 1 milhão de pessoas. Esses dados se referem à execução do programa pelas unidades executoras CONAB, RURALTINS e prefeituras de Araguaína e de Palmas. Os dados referentes ao número de pessoas atendidas em 2003, 2004 e 2010, e sobre a quantidade de alimentos adquirida no ano de 2003, não foram repassados pelas unidades executoras para o MDS, que é responsável pela consolidação e disponibilização dos mesmos para consulta pública.

Até meados de 2003 a CONAB não trabalhava com o público da agricultura familiar. Somente a partir da criação do PAA esse público foi considerado como beneficiários de suas ações. No Estado do Tocantins a CONAB já executou o PAA através de várias modalidades: Compra Direta da Agricultura Familiar; Compra da Agricultura Familiar com Doação Simultânea; Compra Antecipada Especial da Agricultura Familiar; e Formação de Estoque da Agricultura Familiar. No entanto, a partir de 2010, ela passou a executar somente a modalidade Doação Simultânea, 
basicamente com associações formadas por pequenos produtores rurais, pequenos e médios produtores agroextrativistas, produtores de leite de cabra, apicultores, pescadores e mulheres produtoras rurais e urbanas.

No período de 2010 a 2015 , foram executados 80 projetos do PAA via CONAB, com 48 organizações representativas dos agricultores familiares, da quais $98 \%$ eram associações e $2 \%$ eram cooperativas. Percebe-se que, nos últimos seis anos, o programa tem contribuído para o fortalecimento das organizações associativas em detrimentos das cooperativas. Essas, na sua grande maioria, são oriundas de projetos de assentamentos de reforma agrária.

Embora se reconheça a importância do PAA como instrumento para o fortalecimento da agricultura familiar, através da estruturação do sistema de produção dos agricultores, percebe-se que a modalidade Formação de Estoques, considerada estratégica para as cooperativas da agricultura familiar, não está sendo executada pela CONAB e isso, na prática, representa limitações para a organização dessas cooperativas no estado.

\section{Metodologia}

Como já explicamos acima, vamos comparar sistematicamente duas configurações empíricas de mercado institucional da agricultura familiar ${ }^{3}$. Para isso, realizamos "entrevistas semidirigidas" (QUIVY e CAMPENHOUDT, 1992), com agentes em diferentes posições nas configurações, pois, assim, poderemos: acessar suas representações e avaliações; conhecer suas práticas e as práticas de suas organizações; e descobrir e revelar, reconstruindo, alguns processos, agentes e momentos de estabelecimento dos vínculos entre os agricultores, os representantes do estado e os receptores dos produtos.

Realizamos doze entrevistas com os agentes participantes das duas configurações do PAA. Em relação ao PAA Conab, entrevistamos cinco agentes; um líder do Movimento dos Atingidos por Barragens (MAB), dois agricultores familiares, um representante da Associação de Pais e Amigos dos Excepcionais - entidade socioassistencial que recebe

\footnotetext{
${ }^{3}$ O conjunto dos dados está em Carvalho (2016). Aproveitamos para agradecer a CAPES pelo apoio.
} 
as doações do programa - e um gestor público da CONAB. E, em relação ao PAA Estadual, entrevistamos sete agentes; três agricultores familiares, dois gestores públicos do RURALTINS e dois representantes de duas entidades socioassistenciais que recebem as doações do programa - Centro Municipal de Educação Infantil Aconchego e Associação Sementes do Verbo.

Também aplicamos vinte e cinco questionários para fazer uma caracterização dos agricultores familiares, da sua propriedade, da sua produção, etc.: idade, escolaridade, renda, produtos e dimensão da produção, etc. Só responderam os questionários os agricultores participantes das duas configurações analisadas; sete do PAA Conab e dezoito do PAA Estadual.

E, por fim, recorrermos a vários documentos oficiais e não oficiais, especialmente utilizados para descrever as institucionalidades apresentadas nas seções anteriores.

\section{Diferenças morfológicas entre as duas configurações}

Nesta seção, procuramos descrever as características e as relações observadas nos grupos de agentes e nos processos de produção e de comercialização dos agricultores familiares das duas configurações do PAA, sempre procurando contrastá-las.

A situação legal em relação a terra foi a primeira característica verificada junto aos agricultores familiares. No caso do PAA Conab, $86 \%$ dos agricultores declararam serem proprietários da terra e $14 \%$ herdeiros. Em relação ao PAA Estadual, 78\% são proprietários, 11\% herdeiros e $11 \%$ arrendatários, uma característica não presente no PAA Conab. Há também diferenças entre os dois grupos em relação ao tempo de residência na terra; os participantes do PAA Conab residem há cinco anos na mesma propriedade, em média, e os do PAA Estadual há doze anos, em média.

Os herdeiros do PAA Conab e os arrendatários e herdeiros do PAA Estadual são formados por jovens que não têm terra e vivem na propriedade dos pais. $\mathrm{O}$ arrendamento de terras está relacionado a duas questões importantes: o tamanho da propriedade familiar que, em muitos casos, é considerada pequena, levando em conta o tamanho de algumas famílias; e a sucessão geracional no campo, em que alguns 
estudos têm apontado para a necessidade de construir políticas públicas que possam garantir a permanência da população jovem no campo, pois, do contrário, em um curto espaço de tempo restará no campo somente uma população envelhecida. Segundo Brumer (2007), a sucessão geracional na agricultura familiar é importante para a permanência dos jovens no campo, não apenas para os membros da família diretamente envolvidos, mas também para a reprodução das unidades de produção ao longo do tempo.

Quando questionados sobre sua ocupação, os beneficiários fornecedores do PAA Conab só relatam a ocupação de agricultor familiar, no passado e no presente. Isso é diferente no caso dos agricultores do PAA Estadual, uma vez que todos se autodeclararam agricultores familiares, mas seus relatos evidenciam que alguns exerceram outras ocupações anteriormente: motorista, torrador de café, garçom, técnica de enfermagem, técnico de informática, policial, doméstica, pedreiro, vendedor de verdura e professora. Estes dados indicam que os que têm vínculo individual têm origem ocupacional mais diversa do que os que têm vínculo coletivo.

Outra característica analisada foi a divisão dos participantes por sexo. No PAA Conab, $62 \%$ dos participantes são homens e $38 \%$ mulheres. E no PAA Estadual, $72 \%$ são homens e $28 \%$ mulheres. Nos dois casos, prevaleceu a participação de homens. Isso significa que há uma questão de gênero perpassando as condições de participação das mulheres nesse mercado. A maioria dos produtos entregues são produzidos por elas, mas as vendas são feitas em nome dos homens. Isso demonstra que há uma invisibilidade do trabalho das mulheres rurais nas configurações analisadas, um pouco mais acentuada quando o vínculo é individual.

Analisamos também a idade dos agricultores familiares e os agrupamos em três faixas etárias: jovens quando tinham de 15 a 29 anos4; adultos quando tinham de 30 a 59 anos; e idosos quando tinham de 60 anos ou mais ${ }^{5}$. No grupo do PAA Conab, $86 \%$ são adultos e $14 \%$ idosos. No PAA Estadual, a composição etária é um pouco diferente,

4 São considerados jovens, as pessoas com idade entre 15 e 29 anos de idade, segundo a Lei $N^{\circ} 12.852$ de 05 de agosto de 2013, que estabeleceu o Estatuto da Juventude.

5 É considerado idoso, pessoas com idade igual ou superior a 60 anos, segundo Lei $\mathrm{N}^{\circ}$ 10.741 de $1^{\circ}$ de outubro de 2003, que estabeleceu o Estatuto do Idoso. 
pois há um pouco mais de idosos e há jovens; $11 \%$ são jovens, $72 \%$ adultos e $17 \%$ idosos. Ou seja, há uma indicação de que quando o vínculo é individual a diversidade de gerações é maior, com a presença de jovens.

No que se refere à escolaridade, $50 \%$ dos agricultores do PAA Conab têm o ensino fundamental - $20 \%$ completo e $30 \%$ incompleto - e $50 \%$ têm o ensino médio - $40 \%$ completo e $10 \%$ incompleto. No caso do PAA Estadual, 55\% dos agricultores têm ensino fundamental - 11\% completo e $44 \%$ incompleto -, $33 \%$ o ensino médio e $12 \%$ o ensino superior - $6 \%$ completo e $6 \%$ incompleto. Os que têm ou estão cursando o ensino superior são mulheres e jovens em cursos como agronomia e pedagogia. Novamente, quando o vínculo é individual a diversidade é maior, no caso há um número maior dos que têm o ensino fundamental incompleto, ao mesmo tempo que há aqueles que têm ensino superior, nitidamente as mulheres jovens.

Sobre a participação em organizações sociais, os participantes do PAA Conab, além de participarem do MAB, participam de outras duas organizações; $60 \%$ da Associação do reassentamento e 30\% do Sindicato dos Trabalhadores e Trabalhadoras Rurais. Por sua vez, no PAA Estadual, $74 \%$ dos agricultores participam de associações, $16 \%$ de cooperativas e $10 \%$ do Sindicato dos Trabalhadores e Trabalhadoras Rurais. Os agricultores organizados em cooperativas não acessam o PAA por meio delas, mas de forma individual. Isso indica que, na prática, há alguma fragilidade das organizações cooperativas na organização da produção da agricultura familiar, ao passo que outras organizações, como o MAB, associações e sindicatos, estão presentes. Os dois casos analisados também indicam a importância do associativismo para os agricultores familiares, pois eles têm utilizado as associações como mediadoras na comercialização da produção no PAA e no Programa Nacional de Alimentação Escolar (PNAE) - um mercado de alimentação escolar com forte presença do Estado.

A renda dos agricultores familiares participantes do PAA foi analisada a partir de três fontes específicas: vendas de produtos para o PAA; vendas de produtos em outros mercados; e outras rendas como aposentadorias, Programa Bolsa Família, pensões e trabalho assalariado. Conforme a análise dos questionários, a renda familiar dos agricultores participantes do PAA Conab é formada assim: $30 \%$ provém 
das vendas para o PAA; $15 \%$ das vendas para outros mercados; e $55 \%$ de outras rendas, sendo $57 \%$ de aposentadorias, $14 \%$ do Programa Bolsa Família. Todas as aposentadorias são de mulheres. No PAA Estadual a renda familiar é formada assim: 13\% é proveniente das vendas para o PAA; $59 \%$ das vendas para outros mercados, sendo $56 \%$ para o PNAE, 33\% para feiras e $11 \%$ para o mercado convencional; e $28 \%$ de outras fontes, sendo $43 \%$ de aposentadorias, 29\% do Programa Bolsa Família, $14 \%$ de pensões e $14 \%$ de trabalho assalariado realizado dentro da própria comunidade rural. Quando o vínculo é coletivo a formação da renda familiar depende mais do PAA, do Programa Bolsa Família e, especialmente, das aposentadorias. E, inversamente, quando o vínculo é individual a formação depende menos do PAA e de aposentadorias, pensões e Programa Bolsa Família, ao passo que depende mais da venda para outros mercados e também de trabalho assalariado, ainda que em pequena quantidade. No entanto, se considerarmos que mais da metade da venda para outros mercados é realizada para outro programa governamental - PNAE - podemos afirmar que a agricultura familiar vinculada ao PAA tem pouca autonomia de renda vis-à-vis à federação.

Nas duas configurações analisadas, o acesso ao PAA se deu a partir de relações construídas entre os agricultores e as organizações que os assessoram. No caso do PAA Conab, os agricultores foram assessorados pelo $M A B$, que contribuiu de maneira significativa com as discussões sobre o funcionamento do programa e com a elaboração e o acompanhamento da execução do primeiro projeto que foi apresentado à CONAB. No caso do PAA Estadual, os agricultores foram assessorados pelos agentes do RURALTINS que, além de executarem o programa, são também responsáveis pela execução dos serviços de assistência e extensão rural. Dito de outro modo, o vínculo coletivo se deu via associações independentes do estado e o vínculo individual via instituições do Estado do Tocantins.

A sistematização dos dados revelou que os lotes de terra dos agricultores participantes do PAA Conab têm, em média, 36,82 hectares e são lotes de projetos de reassentamentos de atingidos por barragens. Nesse caso, o tamanho dos lotes foi definido pelas disputas das famílias atingidas com o consórcio construtor da barragem. Já os lotes dos agricultores familiares do PAA Estadual não correspondem à metade do 
tamanho dos lotes dos que têm vínculos coletivos, pois têm, em média 16,95 hectares cada um. A maioria dos que têm vínculos individuais são assentados de projetos de assentamentos de reforma agrária e a dimensão dos lotes foi dada por técnicos do Instituto Nacional de Colonização e Reforma Agrária.

Em relação ao acesso às políticas públicas relativas à agricultura familiar, verificamos que os agricultores participantes do PAA Conab têm acesso somente ao PAA. Mas $52 \%$ dos agricultores participantes do PAA Estadual tem acesso ao PNAE, 39\% ao PRONAF e 9\% Pronaf Mulher. Os que têm vínculos coletivos têm menos circuitos de acesso às políticas governamentais, ao passo que os que têm vínculos individuais estão em uma situação mais vantajosa se considerarmos que, além do PAA e PNAE, têm acesso a outras políticas consideradas estratégicas para a estruturação do sistema produtivo, a assistência técnica e o crédito.

Quando questionados sobre a produção agroecológica, 57\% dos agricultores participantes do PAA Conab afirmaram trabalharem com esse tipo de produção e $43 \%$ afirmaram que não trabalham. Em relação aos do PAA Estadual, $61 \%$ trabalham com produção agroecológica e $39 \%$ não trabalham. A diferença é pequena e pode ser atribuída ao fato de que os que têm vínculos individuais terem mais acesso a outros mercados que aceitam esses produtos. No Tocantins, ainda que os agricultores trabalhem com este tipo de produção, o PAA não paga o preço estabelecido para esse tipo de produto porque os agricultores não têm os documentos de comprovação de origem.

\section{As formas e práticas de vínculos no mercado}

Nesta seção vamos descrever diversos processos modais mais específicos do processo mais geral de construir e estabilizar as relações entre os agricultores familiares e o PAA, ou o mercado institucional da agricultura familiar. O processo mais geral é como uma corda formada por fios modais. Mas a força dessa corda não se reduz a nenhum dos seus fios em particular. Procuraremos descrever cada um desses processos comparando a configuração coletiva e individual.

Sobre a comercialização da produção dos agricultores familiares, há três canais de comercialização acessados pelos agricultores. Um é 
menos recorrente; a venda direta ao consumidor na rua, mesmo quando participa do PAA. Outro que é recorrente e que era mais acessado antes do PAA, mas que continua como alternativa é o atravessador. A venda da produção para o atravessador parece estar relacionada à falta de condições de acesso a outros mercados, principalmente pela inexistência de transporte. E, por fim, outro canal de comercialização é a feira. As relações com a feira são variadas. Por um lado, ela é um espaço em que não ocorrem relações apenas comerciais, mas também onde relações de confiança e proximidade são construídas. Por outro lado, existem agricultores que não frequentam a feira porque o retorno financeiro não é suficiente para compensar toda a logística necessária para participarem de tal mercado. Não pudemos descrever diferenças de práticas entre os dois grupos em relação a esses canais de comercialização. O que pudemos observar aponta que as dificuldades de logística são relevantes para o direcionamento que os agricultores dão à sua produção.

Ainda em relação à comercialização, questionamos os agricultores sobre os motivos que os levaram a se vincularem ao PAA. Conforme os relatos apresentados, a participação dos agricultores no PAA está relacionada à busca de mercado para escoar a produção que estava "perdendo" ou que, por ser considerada de pequena escala, não dava para comercializar com os grandes mercados. Ainda, para além da quantidade, tem também o custo do transporte que, em muitos casos, inviabiliza a comercialização da produção dos agricultores familiares para os mercados convencionais. E, em complemento a isso, alguma garantia dada pelo PAA em termos de pagamento e previsibilidade também influenciou na decisão de participar - "uma garantia, apesar que não é grande coisa". E, por fim, alguma influência das associações que permitiam e, de certa forma, os orientavam a refletirem sobre as vantagens e desvantagens da participação - "reunimos, conversamos com os produtores qual é a vantagem?".

Em relação à seleção dos beneficiários fornecedores, a primeira exigência a ser cumprida é que os agricultores tenham a Declaração de Aptidão, documento que qualifica os agricultores familiares para acessarem as políticas públicas destinadas à agricultura familiar, principalmente o PRONAF. Outra condição é que os agricultores estejam residindo na terra e tenham produção para vender. $\mathrm{E}$, no caso de acesso 
ao programa de forma coletiva, os agricultores devem estar vinculados a uma associação ou cooperativa. O processo de seleção dos agricultores, quando o vínculo é individual, apresenta dois aspectos diferentes: prioriza a participação dos agricultores que têm menor renda; encontra dificuldades relacionadas à participação das mulheres no programa, que têm cota de $30 \%$ a $40 \%$, estabelecida pelo GGPAA.

Além da seleção dos agricultores, outro aspecto importante é a seleção dos produtos. No caso do PAA Conab, ela é feita de modo tripartite; com agentes da unidade executora, beneficiários fornecedores e consumidores. Dito de outro modo, os produtores negociam com os que recebem a doação, no caso a Associação de Pais e Amigos dos Excepcionais, com a mediação de agentes da CONAB e do MAB. Assim, quando o vínculo é coletivo, há um envolvimento direto de todos, que procuram estabelecer regras - produtos, quantidades, qualidade, prazos - que todos possam cumprir. No PAA Estadual, a seleção dos produtos é feita pelos técnicos dos escritórios locais do RURALTINS. Eles identificam a existência de produção local para o atendimento das demandas das entidades. A seleção da cesta de produtos parte de um procedimento mais técnico, pois não conta com o envolvimento direto dos agricultores e das entidades que vão receber as doações.

Sobre a entrega dos produtos, verificamos que, no caso do PAA Conab, eles são entregues no reassentamento. No local, é feita a pesagem, sob as vistas do agricultor, do representante do MAB e da Associação de Pais e Amigos dos Excepcionais. Desse modo, neste encontro ritual dos agentes deste mercado - vendedor, assessoria da associação e consumidor, respectivamente -, gera-se credibilidade e controle sobre a quantidade e a origem dos produtos entregues e não se registra conflitos explícitos e rompimento das relações. E, ainda, gera-se novas regras entre os participantes, além das estabelecidas pelos agentes e processos administrativos governamentais. $O$ relato de um entrevistado é um exemplo paradigmático. Segundo ele, um agricultor não cumpriu a cota de produtos no momento da entrega, mas se comprometeu, perante todos, a entregar o restante na semana subsequente. A proposta foi aceita por todos os presentes e a entrega foi realizada.

Além da pesagem, do prazo e da conferência da qualidade, a definição dos preços é um assunto e um ponto importante na relação 
dos agentes. Nas discussões, ficam relevantes os elementos relacionados à metodologia utilizada para definir os preços. A definição dos preços se dá a partir do envolvimento da CONAB e do RURALTINS, executores do programa no estado, que seguem as orientações do GGPAA. Os gestores públicos afirmam a legitimidade dos preços com base na metodologia adotada; uma pesquisa em três mercados, a partir da qual são consolidados os preços de todos os produtos em uma tabela única que é utilizada em todo o estado. Mas a definição dos preços é questionada pelos agricultores nas duas configurações analisadas.

Os agricultores participantes do PAA Estadual apresentam um ponto de discordância, de conflito; questionam a forma como é feita a pesquisa de preço dos produtos. Eles consideram que os preços são baixos e argumentam que isso se deve ao fato de que a pesquisa é feita no "mercado que tá de promoção". Os agricultores participantes do PAA Conab, compartilham as mesmas considerações sobre os preços baixos dos produtos. Mas reconhecem que o preço é definido dentro do Estado do Tocantins e é repassado pela CONAB, através de uma tabela. Nesse caso, eles relatam outra estratégia para tentar modificar os preços ou sair de algumas relações de venda menos vantajosas. Eles identificam, na lista de preços, os produtos com preços abaixo do mercado que conhecem, que têm como referência. E, assim, procuram não colocar no projeto, os produtos que devem ser entregues ao programa - a renovação do convênio agricultura familiar e PAA é periódica.

Contestar os preços ou tirar um produto da lista dos possíveis, assim como, monitorar a qualidade, o prazo e a quantidade dos produtos, são momentos estruturais e ilustrativos para percebermos como os agricultores tem se comportado diante das regras formais desse mercado: respeitam e cumprem; tentam modificar; inventam novas, paralelas e até mesmo contraditórias; contornam ou flexibilizam as existentes, etc. Há um leque de combinações que não estão inscritas nas normas do programa. Elas são relações e institucionalidades construídas no dia a dia, nos rituais. Tácita ou explicitamente, elas são tão importantes para a sobrevida dos vínculos, das relações neste mercado, como são os recursos financeiros do governo federal. Parafraseando Durkheim, elas mobilizam inúmeras condições não contratuais do contrato (1999). 
No que tange à análise de como é feito o pagamento dos produtos, temos que ele é feito conforme o modo que os agricultores acessam o programa; de modo pessoal quando o vínculo é coletivo e impessoal quando é individual. Em relação aos agricultores do PAA Conab, o pagamento é realizado num prazo de dez dias, mais ou menos, a contar da data de entrega da documentação pela associação do reassentamento na CONAB. Depois, o repasse é feito à associação, que em seguida faz o pagamento aos agricultores, em dinheiro e em mãos - representante da associação saca os recursos no banco e os distribui. Vale registrar que, quando o projeto iniciou, alguns agricultores não tinham conta bancária e nem se interessaram em abrir uma para receber seus pagamentos. Ao contrário dos agricultores do PAA Estadual que têm conta bancária e cartão personalizado do PAA, e, assim, sacam individualmente o pagamento de suas vendas.

Quando questionados sobre as dificuldades relacionadas à participação no PAA, os agricultores do PAA Conab citaram apenas duas: organizar os documentos para participar do programa; e atrasos no pagamento dos produtos devidos às paralizações no projeto para adequação de alguns beneficiários fornecedores - por exemplo, o caso de casas de farinhas de três deles. Ou seja, quando o vínculo é coletivo, os desajustes individuais acabam repercutindo na coletividade. No entanto, para os agricultores participantes do PAA Estadual, há mais dificuldades tidas como principais: falta de selo para os produtos processados; baixo preço dos produtos; falta de uma central de distribuição para facilitar as entregas dos produtos; falta de calendário fixo para abrir as vendas; atraso nos pagamentos; transporte dos produtos para as entidades. Enfim, os dois tipos de vínculo compartilham a referência a algumas dificuldades como atraso no pagamento e o baixo preço dos produtos. Quando o vínculo é coletivo, a construção das relações é tida como um pouco difícil por conta da parte burocrática, da mobilização dos documentos. Quando o vínculo é individual, a construção das relações esbarra em mais constrangimentos.

\section{Considerações finais}


Apresentamos o formato institucional do PAA na sua relação com a agricultura familiar e um balanço, em forma de série histórica, dos recursos financeiros direcionados ao programa e das atividades econômicas geradas, produção e consumo de alimentos e quantidade de pessoas e famílias envolvidas, dentre outras.

Uma das observações importantes é que o mercado da agricultura familiar, em alguma medida, dinamizou as atividades dos agricultores familiares, mas não gerou alterações expressivas nas suas fontes de renda.

Apresentamos descrições da morfologia dos grupos que acessaram o PAA, de modo coletivo ou individual. De modo geral, em comparação, na configuração coletiva os indivíduos são mais homogêneos, enquanto na individual são mais heterogêneos escolaridade, renda, formação escolar, inserção econômica, etc.

Em relação às práticas e representações dos agentes das duas configurações, também verificamos tomadas de posição diferentes seleção de beneficiários e produtos, contornar de processos de formação de preços, receber os pagamentos, etc. - e dificuldades compartilhadas, por exemplo, as questões de logística.

E, por fim, em ambas configurações os agentes interagem e criam normatividades locais que são tão importantes para a configuração do mercado quanto as normas formais e os montantes de recursos financeiros disponibilizados.

\section{REFERÊNCIAS}

BOURDIEU, Pierre. Les structures sociales de l'économie. Paris: Seul, 2000.

BRASIL. Lei $\mathrm{N}^{\circ} 10.696$, de 2 de julho de 2003 - Dispõe sobre a repactuação e o alongamento de dívidas oriundas de operações de crédito rural, e dá outras providências. Disponível em: http://www.planalto.gov.br/ccivil_03/leis/2003/L10.696.htm. Acesso em: 14 jun. 2015.

Lei $\mathrm{N}^{0} 11.346$, de 15 de setembro de 2006 - Cria o Sistema Nacional de Segurança Alimentar e Nutricional - SISAN com vistas em 
assegurar o direito humano à alimentação adequada e dá outras providências.

Disponível

em:

http://www.planalto.gov.br/ccivil_03/_ato2004-

2006/2006/lei/l11346.htm. Acesso em: 14 jun. 2015.

Lei $\mathrm{N}^{\circ} 11.326$, de 24 de julho de 2006 - Estabelece as diretrizes para a formulação da Política Nacional da Agricultura Familiar e Empreendimentos Familiares Rurais.

Decreto $\mathrm{N}^{0} 7.775$, de 4 de julho de 2012 - Regulamenta o art. 19 da Lei $\mathrm{N}^{\circ}$. 10.696, de 2 de julho de 2003, que institui o Programa de Aquisição de Alimentos, e o Capítulo III da Lei $\mathrm{N}^{\circ} 12.512$, de 14 de outubro de 2011, e dá outras providências. Disponível em: http://www.planalto.gov.br/ccivil_03/_ato20112014/2012/Decreto/D7775.htm Acesso em: 25 jan. 2016.

. Lei $\mathrm{N}^{0} 12.852$ de 05 de agosto de 2013, institui o Estatuto da Juventude e dispõe sobre os direitos dos jovens, os princípios e diretrizes das políticas públicas de juventude e o Sistema Nacional de Juventude - SINAJUVE. Disponível em: http://www.planalto.gov.br/ccivil_03/_Ato20112014/2013/Lei/L12852.htm. Acesso em: 25 jan. 2016.

Decreto $\mathrm{N}^{\circ} 8.293$, de 12 de agosto de 2014. Altera o Decreto no 7.775, de 4 de julho de 2012, que dispõe sobre o Programa de Aquisição de Alimentos. Disponível em: http://www.planalto.gov.br/ccivil_03/_ato20112014/2014/Decreto/D8293.htm. Acesso em: 18 jul. 2015.

Companhia Nacional de Abastecimento (CONAB). Grupo Gestor do Programa de Aquisição de Alimentos (GGPAA). Resolução No 49 de 25 de setembro de 2012, instituiu o Comitê Consultivo, para assessoramento e acompanhamento das atividades do PAA. Disponível em:

http://www.conab.gov.br/OlalaCMS/uploads/arquivos/12_10_25_10_57 _37_resolucao_no_49-_de_25_de_setembro_de_2012.pdf. Acesso em: 06 jul.2015. 
BRUMER, Anita. A problemática dos jovens rurais na pós-modernidade. In: CARNEIRO, M. J.; CASTRO, E. G. (Org.). Juventude rural em perspectiva. Rio de Janeiro: Editora Mauad, 2007.

CARVALHO, Gildene S. O Programa de Aquisição de Alimentos (PAA) no Tocantins - Análise das condições sociais de realização e funcionamento a partir de experiências concretas: PAA Conab versus PAA Estadual. 2016. 223f. Dissertação (Mestrado em Desenvolvimento Regional) Programa de Pós-Graduação em Desenvolvimento Regional, Universidade Federal do Tocantins, Palmas - TO, 2016.

DURKHEIM, Émile. Da divisão do trabalho social. São Paulo: Martins Fontes, 1999.

FLIGSTEIN, Neil. O Mercado enquanto política: Uma abordagem políticocultural as instituições de mercado. In: MARQUES, Rafael, PEIXOTO, João. A Nova Sociologia Econômica. Celta Editora, Oeiras, 2003.

FLIGSTEIN, N.; DAUTER, L. A sociologia dos Mercados. Caderno CRH, Salvador, v. 25, 66, p. 481-504, Set/Dez. 2012.

GARCIA-PARPET, Marie France. A construção social de um mercado perfeito: o caso de Fontaines-en-sologne. Estudos Sociedade e Agricultura, 20, abril 2003, p. 5-44, 2003.

---_--. Representações científicas e práticas mercantis camponesas. Raízes, v. 21, n. 2, p. 01-16, 2002.

GRISA, Catia. As redes e as instituições do Programa de Aquisição de Alimentos (PAA). In: Revista Brasileira de Gestão e Desenvolvimento Regional, Volume 6, N² 2, p.97-129, mai-ago/2010, Taubaté, SP, Brasil, 2010.

POLANYI, Karl. A grande transformação. Rio de Janeiro: Campus, 2000.

QUIVY, R.; CAMPENHOUDT, L. V. Manual de investigação em ciências sociais. Editora: Gravida, 1992. 
SWEDBERG, Richard. Principles of Economic Sociology. Princeton, EUA: Princeton University Press, 2003.

Submetido em 30/03/2016

Aprovado em 19/08/2016

\section{Sobre os autores}

\section{Gildene Soares Carvalho}

Historiadora, mestre em Desenvolvimento Regional pela Universidade Federal do Tocantins - UFT. Consultora em Desenvolvimento Rural Sustentável no Instituto Interamericano de Cooperação para a Agricultura (IICA).

E-mail: gil.carvalho9@hotmail.com

\section{Antônio José Pedroso Neto}

Sociólogo, doutor em ciências sociais pela UFSCar; estágio sanduíche na EHESS/Paris; e pós-doutorado na FACE/CEDEPLAR/UFMG. Professor adjunto IV da UFT. Bolsista de produtividade do CNPq desde 2009.

E-mail: ajpedrosoneto@uol.com.br 